\title{
Immobilization of magnetite nanoparticles for the removal of arsenic and antimony from contaminated water
}

\author{
G. Sun \& M. Khiadani \\ School of Engineering, Edith Cowan University, Joondalup, WA, Australia
}

\begin{abstract}
Magnetite $\left(\mathrm{Fe}_{3} \mathrm{O}_{4}\right)$ nanoparticles were synthesized and immobilized in a synthetic resin polymethyl methacrylate (PMMA). The $\mathrm{Fe}_{3} \mathrm{O}_{4}$ nanoparticle-PMMA composites were studied for their efficiencies of removing dissolved arsenic (As) and antimony ( $\mathrm{Sb}$ ). The effects of major environmental and operating parameters on the removal of $\mathrm{As}$ and $\mathrm{Sb}$ were investigated in batch experiments. Singular and competitive adsorption of $\mathrm{As}$ and $\mathrm{Sb}$ onto the composites were studied. The results demonstrated the capability of the $\mathrm{Fe}_{3} \mathrm{O}_{4}$-PMMA composites for removing dissolved metalloids.
\end{abstract}

\section{INTRODUCTION}

Dissolved metalloids, including As and $\mathrm{Sb}$, can be present in contaminated surface waters or groundwater. The health risk posed by arsenic, in particular when it is in inorganic dissolved form, has been widely recognized. Antimony is considered an emerging contaminant that is linked to skin, lung, and eye diseases (Cooper \& Harrison, 2009). The removal of these metalloids from contaminated waters is essential for protecting human health and the environment.

A variety of methods have been studied for the removal of the two metalloids, including adsorption, membrane, coagulation/flocculation, oxidation/ precipitation, etc. Among these methods, adsorption is considered a low cost conventional technique. Various high-tech or low-tech adsorbents, such as synthetic resins, activated carbon, agro-wastes, and mineral clays, etc., have been studied in lab experiments (Ungureanu et al., 2015). Currently, many researchers are focusing their efforts on discovering innovative adsorbents, to further enhance adsorption efficiency and reduce cost.

Magnetite $\left(\mathrm{Fe}_{3} \mathrm{O}_{4}\right)$ nanoparticles have the potentially to be used as an adsorbent or electron donor for the removal of water contaminants, due to their high surface areas, reactivity and well-established synthesis methods. Another advantage of the magnetite-based adsorbents is that they can be recovered through magnetic field. Their disadvantages include mobility in water, agglomeration, and oxidation by non-target compounds in water; these have limited the application of iron-based nanoparticles to treat contaminated waters. Appropriate methods of applying the particles, such as entrapment in porous media or carriers, need to be investigated. In this study, comparative experiments were carried out to study the efficiency of magnetite nanoparticles immobilized in a synthetic PMMA resin for the adsorption of $\mathrm{As}$ and $\mathrm{Sb}$.

\section{MATERIALS AND METHODS}

\subsection{Synthesis of magnetite nanoparticles}

AR grade ferric chloride hexahydrate $\left(\mathrm{FeCl}_{3} \cdot 6 \mathrm{H}_{2} \mathrm{O}\right)$, ferrous chloride tetrahydrate $\left(\mathrm{FeCl}_{2} \cdot 4 \mathrm{H}_{2} \mathrm{O}\right)$, 2-(4chlorosulfonylphenyl) ethyl-trichlorosilane (CTCS), methyl methacrylate (MMA), and 30\% ammonium hydroxide $\left(\mathrm{NH}_{4} \mathrm{OH}\right)$ were purchased from Sigma Aldrich. Milli-q water was produced by a Merck Millipore instrument. Magnetic iron oxide nanoparticles were synthesized by co-precipitation of $\mathrm{Fe}^{2+}$ and $\mathrm{Fe}^{3+}$ ions to form $\mathrm{Fe}_{3} \mathrm{O}_{4}$ precipitates via the following reaction.

$\mathrm{Fe}^{2+}+2 \mathrm{Fe}^{3+}+8 \mathrm{OH}^{-} \rightarrow \mathrm{Fe}_{3} \mathrm{O}_{4} \downarrow+4 \mathrm{H}_{2} \mathrm{O}$

$4.31 \mathrm{~g}$ of ferrous chloride tetrahydrate and $11.68 \mathrm{~g}$ of ferric chloride hexahydrate were added into a reaction chamber $(500 \mathrm{~mL}$ triple neck round bottomed flask) pre-filled with $200 \mathrm{ml}$ water (deoxygenated by purging with $\mathrm{N}_{2}$ gas). The chamber was connected to a condenser and a mechanical mixer and placed in an oil bath. Ammonium hydroxide solution was gradually (dropwise) added to the solution. The color of the solution gradually changed from orange to dark brown and finally black. This was continued until the $\mathrm{pH}$ reached 8.0. A magnet was used to separate solid precipitates of $\mathrm{Fe}_{3} \mathrm{O}_{4}$ from the solution. The $\mathrm{Fe}_{3} \mathrm{O}_{4}$ precipitates were rinsed repeatedly with milli-q water and saline $(0.1 \mathrm{M}$ $\mathrm{NaCl}$ ) water, vacuum-dried and stored. 


\subsection{Synthesis and characterization of $\mathrm{Fe}_{3} \mathrm{O}_{4}$-PMMA composite}

Three grams of the $\mathrm{Fe}_{3} \mathrm{O}_{4}$ precipitates were mixed in $40 \mathrm{~mL}$ of dehydrated toluene. $1.3 \mathrm{mmol}$ CTCS was added to the solution, and kept in room temperature for $24 \mathrm{~h}$, to produce $\mathrm{Fe}_{3} \mathrm{O}_{4}$ particles immobilized with CTCS. The particles were separated from the solution, washed, dried and weighted. For polymerization, $1.6 \mathrm{~g}$ of these particles were added to $80 \mathrm{~mL}$ toluene and mixed with $50 \mathrm{~g}$ MMA in the reaction chamber in $\mathrm{N}_{2}$ environment. The reactor was submerged in the oil bath at $80^{\circ} \mathrm{C}$, and the solution was stirred by a mechanical impeller for $4 \mathrm{~h}$. By the end of the polymerization period, magnetic composites in the liquid were separated by the magnet, collected, washed, centrifuged, and dried. Surface characteristics of the $\mathrm{Fe}_{3} \mathrm{O}_{4}$ nanoparticles and $\mathrm{Fe}_{3} \mathrm{O}_{4}$-PMMA composites were analyzed by a scanning electron microscope (JCM-6000, JOEL). An X-ray powder diffraction apparatus (PANAnalytical) was used to analyze the chemical compositions of the $\mathrm{Fe}_{3} \mathrm{O}_{4}$ nanoparticles.

\subsection{Batch testing of As and Sb removal by the nanoparticles}

An arsenic stock solution was prepared by diluting $1000 \mathrm{mg} \mathrm{L}^{-1}$ As(III) standard solution (Agilent) to $100 \mathrm{mg} \mathrm{L}^{-1}$. An $274 \mathrm{mg} \mathrm{L}^{-1}$ antimony (III) stock solution by dissolving measured amount of antimony potassium tartrate $\mathrm{K}_{2} \mathrm{Sb}_{2}\left(\mathrm{C}_{4} \mathrm{H}_{2} \mathrm{O}_{6}\right) 2.3 \mathrm{H}_{2} \mathrm{O}$ in milli-q water. A series of batch adsorption tests were then carried out to study $\mathrm{As}$ and $\mathrm{Pb}$ removal by the $\mathrm{Fe}_{3} \mathrm{O}_{4}$ nanoparticles, in mobile (bare particles) and PMMA immobilized forms. The batch adsorption studies were carried out using $100 \mathrm{~mL}$ flasks, each filled with $50 \mathrm{~mL}$ of As, $\mathrm{Sb}$, or mixed As and Sb solutions, which were placed on an orbital shaker rotated at $180 \mathrm{rpm}$ for 90 minutes. As and $\mathrm{Pb}$ concentrations of the solutions, at the beginning and end each batch test, were analyzed by a MP-AES instrument (Agilent).

\section{RESULTS AND DISCUSSION}

\subsection{Characteristics of the synthesized nanoparticles and $\mathrm{Fe}_{3} \mathrm{O}_{4}$-PMMA Composites}

Figure 1 shows the surface of the synthesized nanoparticles and $\mathrm{Fe}_{3} \mathrm{O}_{4}$-PMMA composites. It appears that the sizes of the particles were indeed in $\mathrm{nm}$ range. The $\mathrm{Fe}_{3} \mathrm{O}_{4}$ impregnated PMMA composites were observed to have more rugged surfaces, compared with the surfaces of blank (without particle impregnation) MMA polymer.

XRD analyses of the synthesized nanoparticles and a commercial $\mathrm{Fe}_{3} \mathrm{O}_{4}$ sample produced similar profiles. Both synthesized and commercial samples had six significant diffraction peaks observed in both samples (at $2 \theta$ of $511,442,440,400,311$ and 220), confirming the presence of hematite in the synthesized nanoparticles.

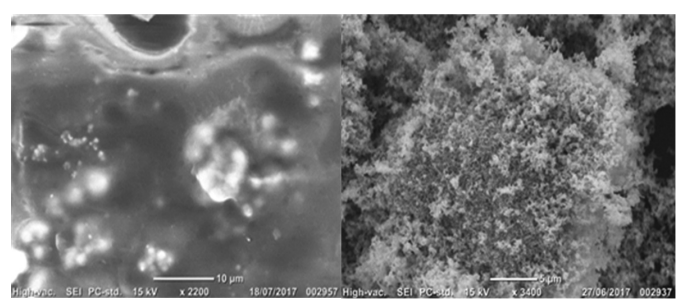

Figure 1. The SEM images of the $\mathrm{Fe}_{3} \mathrm{O}_{4}$ nanoparticles (left) and $\mathrm{Fe}_{3} \mathrm{O}_{4}$-PMMA composites (right).

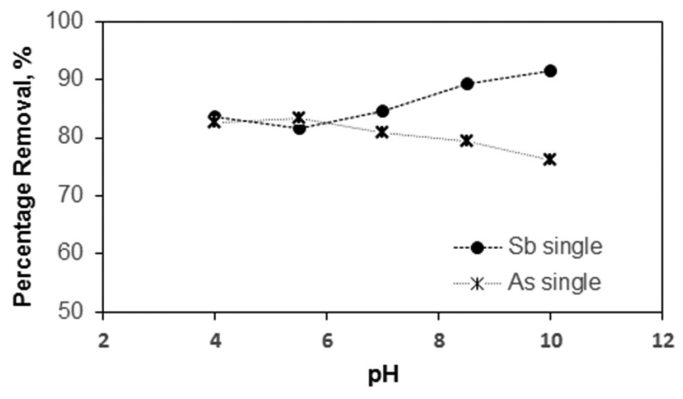

Figure 2. Percentage removal of $\mathrm{As}$ and $\mathrm{Sb}$ by the $\mathrm{Fe}_{3} \mathrm{O}_{4}$-PMMA composites at different $\mathrm{pH}$.

\subsection{Batch testing results of As and $S b$ removal}

Figure 2 shows the percentage removal of As and $\mathrm{Sb}$ at different $\mathrm{pH}$, when $\mathrm{As}$ and $\mathrm{Sb}$ were present as single contaminants in separate solutions. Efficiencies of commercial and synthesized nanoparticles, dosage, and co-existence (competitive removal) of these metalloids were also investigated.

\section{CONCLUSION}

Magnetite nanoparticle-PMMA composites were synthesized and tested for the removal of As and Sb. The results demonstrated their potential as an effective, recoverable adsorbent for in situ remediation of metalloid contaminated water.

\section{ACKNOWLEDGEMENTS}

The authors acknowledge Mr. Seyed Seyedi and Mr. Willie Tan, who contributed to the experiments.

\section{REFERENCES}

Cooper, R.G. \& Harrison, A.P. 2009. The exposure to and health effects of antimony. Indian J. Occup. Environ. Med. 13(1): 3-10.

Ungureanu, G., Santos, S., Boaventura, R. \& Botelho, C. 2015. Arsenic and antimony in water and wastewater: overview of removal techniques with special reference to latest ad-vances in adsorption. J. Environ. Manag. 151: 326-342. 


\title{
Arsenic retention on technosols prepared with nanoparticles for treatment of mine drainage water
}

\author{
D. Bolaños ${ }^{1}$, V. Sánchez ${ }^{1}$, J. Paz ${ }^{2}$, M. Balseiro ${ }^{3}$ \& L. Cumbal ${ }^{2,4}$ \\ ${ }^{1}$ Department of Earth and Construction Science, Universidad de las Fuerzas Armadas ESPE, Sangolqui, Ecuador \\ ${ }^{2}$ Department of Life Science and Agriculture, Universidad de las Fuerzas Armadas ESPE, Sangolquí, Ecuador \\ ${ }^{3}$ Department of Chemical Engineering, Centre for Research in Environmental Technologies (CRETUS), \\ Universidade de Santiago de Compostela, Spain \\ ${ }^{4}$ Center of Nanoscience and Nanotechnology (CENCINAT), Universidad de las Fuerzas Armadas ESPE, \\ Sangolquí, Ecuador
}

\begin{abstract}
Arsenic (As) concentrations of 4.8 to $27.5 \mu \mathrm{g} \mathrm{L}^{-1}$ have been detected in wastewater of gold mines in southern Ecuador (Portovelo) thus there is a need of applying remediation techniques to avoid superficial and groundwater contamination. In this study we have prepared a technosol composed by a ferric soil collected in the mining area and multicomponent nanoparticles synthetized using sodium borohydride and orange peel extract as co-reductants. The sorption capacity of the technosol was experimentally characterized using sorption isotherms. Langmuir model fits the experimental results and its parameters such as maximum sorption capacity and adsorption bond energy are $71185 \mathrm{mg} \mathrm{kg}^{-1} 7.50 \mathrm{~kg} \mathrm{mg}^{-1}$, respectively. Based on these preliminary results, it seems that the as-prepared technosol will be a cheap cost solution for capturing arsenic from the mine drainage water.
\end{abstract}

\section{INTRODUCTION}

Mine drainage water usually contains high concentrations of heavy metals and other compounds. Due to poor handling, this contaminated water may leach and migrate to ground and spring water, becoming a potential contaminant of drinking water sources (Bolaños, 2015; Polizzotto et al., 2006). There are many available technologies to cleanup As-contaminated water, whose efficiency and applicability will mainly depend on the chemical form of As in water (Cumbal, 2004). Adsorption of As in specific sorbents has been widely used due to its high versatility, easy operation and handling, and low costs. The application of specifically "tailored" technosols, composed of soil components and non-harmful residues with sorption capacities for specific contaminants, has shown successful results on the restoration of degraded mining areas contaminated with a wide variety of trace metals and metalloids (Macías, 2012). On the other hand, nanosorbents has emerged as a promising alternative for the cleanup of As-contaminated water (zero valent iron and iron oxide nanoparticles), because of their distinctive and advantageous properties, such as the small size, high surface area, and high reactivity due to the large number of sorption active sites (Pérez-Esteban et al., 2016).

The objective of the present study was to find out the arsenic sorption capacity of a tailored technosol composed of a ferralsol, with $25,531 \mathrm{mg} \mathrm{kg}^{-1}$ of Fe ( $2 \% w / w$, associated to Fe and Mn oxides) and multicomponent nanoparticles.

\section{METHODS}

Water samples were collected at three discharges of artesian gold-processing plants located in the border of the Amarillo River (Portovelo, Ecuador), the main collector of liquid wastes from the gold-processing artesian plants. $\mathrm{pH}, \mathrm{Eh}$, electric conductivity were measured on site and heavy metals and As were analyzed with an atomic absorption spectrometer using standardized methods. For the fabrication of multicomponent nanoparticles (MCNPs) $\mathrm{FeCl}_{3} \cdot 6 \mathrm{H}_{2} \mathrm{O}$ and $\mathrm{Na}_{2} \mathrm{SO}_{4}$ solutions were mixed and purged with nitrogen. Then, $\mathrm{NaBH}_{4}$ and orange peel extract were added as co-reductants. The technosol was prepared mixing $12.5 \mathrm{mg}$ of MCPNPs and 4,987.5 mg of soil. Arsenic sorption was performed in batch tests mixing $5 \mathrm{~g}$ of technosol with $100 \mathrm{~mL}$ of arsenic contaminated water at neutral $\mathrm{pH}$.

Mine drainage water was doped with six different concentrations of arsenic (25, 50, 100, 200, 400, $\left.600 \mu \mathrm{g} \mathrm{L}^{-1}\right)$. The amount of arsenic sorbed on the technosol was determined by mass balance using the equation (Vanderborght \& Van Grieken, 1977):

$\mathrm{q}=\mathrm{V} / \mathrm{m}\left(\mathrm{C}_{\mathrm{i}}-\mathrm{C}_{f}\right)$

where $\mathrm{q}=$ concentration of As in the soil, $\mathrm{V}=$ volume of water contaminated with As, $\mathrm{m}=$ mass of soil and $\mathrm{C}_{i}$ and $\mathrm{C}_{f}$ initial and final As concentrations. 